\title{
Measurement and Correlation for Solubility of Some Pyrimidine Derivatives in Different Solvents
}

\author{
Kapil Bhesaniya and Shipra Baluja \\ Physical Chemistry Laboratory, Department of Chemistry, Saurashtra University, Rajkot, Gujarat 360005, India \\ Correspondence should be addressed to Shipra Baluja; shipra_baluja@rediffmail.com
}

Received 15 August 2013; Accepted 9 December 2013; Published 3 March 2014

Academic Editor: Zhen Zhao

Copyright (C) 2014 K. Bhesaniya and S. Baluja. This is an open access article distributed under the Creative Commons Attribution License, which permits unrestricted use, distribution, and reproduction in any medium, provided the original work is properly cited.

\begin{abstract}
Some new pyrimidine derivatives have been synthesized and their characterization was done by IR, NMR, and mass spectral data. The solubility of these synthesized compounds has been studied in methanol, $N, N$ dimethylformamide (DMF), and carbon tetrachloride $\left(\mathrm{CCl}_{4}\right)$ by gravimetrical method from 298.15 to $328.15 \mathrm{~K}$ under atmospheric pressure and the solubility data were correlated against temperature. The solubility is found to increase with temperature and order of solubility is DMF $>$ methanol $>$ $\mathrm{CCl}_{4}$. The experimental solubility data is correlated with the modified Apelblat equation. Some thermodynamic parameters such as dissolution enthalpy, Gibbs energy of dissolution, and entropy of mixing have also been calculated.
\end{abstract}

\section{Introduction}

The pyrimidine ring is an important structure in numerous natural products and bioactive compounds [1]. Further, the pyrimidine nucleus is present as a building block in materials science $[2,3]$. Literature survey reveals that as pharmacologically active compounds, substituted pyrimidine scaffolds have become increasingly important with antimicrobial $[4$, 5], antimalarial [6], anticancer [7], and antimycotic activities [1].

So, it will be interesting to study their solubility in different solvents due to their various applications, which may help their uses in other fields also. Thus, in the present paper, solubility of some pyrimidine derivatives in methanol, DMF, and $\mathrm{CCl}_{4}$ from 298.15 to $328.15 \mathrm{~K}$ has been studied at atmospheric pressure. Some thermodynamic parameters such as dissolution enthalpy, Gibbs energy of dissolution, and entropy of mixing have also been calculated.

\section{Experimental}

2.1. Materials. The choice of solvent depends upon solubility and relative permeability. 2,4-Dichloropyrimidine (DCP) (CAS no.: 3934-20-1) and 4-((1H-1,2,4-triazol-1yl)methyl)aniline (TMA) (CAS no.: 119192-10-8) used in the synthesis were purchased from Sigma-Aldrich. N,Ndiisopropylethylamine (DIPEA) (CAS no.: 7087-68-5), the solvents methanol, dimethylformamide (DMF), and carbon tetrachloride $\left(\mathrm{CCl}_{4}\right)$ used in the present work were of $\mathrm{AR}$ grade supplied by Spectrochem Pvt. Ltd. (Mumbai, India) and were purified according to the standard procedure [8]. The purity of solvents was checked by GC-MS (SHIMADZUModel no.-QP-2010) and found to be greater than $99.0 \%$.

2.2. Synthesis. A mixture of 2,4-dichloropyrimidine (DCP) (1.0 equi.), 4-((1H-1,2,4-triazol-1-yl)methyl)aniline (TMA), and $\mathrm{N}, \mathrm{N}$-diisopropylethylamine (DIPEA) (1.2 equi.) in $\mathrm{n}$ Butanol was refluxed for $3 \mathrm{~h}$. The completion of reaction was confirmed by analytical thin layer chromatography (TLC). After completion of reaction, reaction mass was cooled and the resulting solid was filtered, washed with cold water, and dried in vacuo to give crude product.

This resulting product was refluxed for $3 \mathrm{~h}$ with ethanolic solution of different aromatic amines (1.1 equi.) in presence of glacial acetic acid (2-3 drops). After completion of reaction, the reaction mass was cooled and the resulting solid was filtered, washed with cold ethanol, and dried in vacuo to give crude product. The obtained crude product was purified by trituration with diethyl ether and purity of all these synthesized compounds was checked by TLC (performed on 
<smiles>Clc1ccnc(Cl)n1</smiles>

DCP<smiles>Nc1ccc(Cn2cncn2)cc1</smiles>

TMA

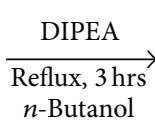
n-Butanol

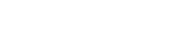<smiles>Clc1nccc(Nc2ccc(Cn3cnnn3)cc2)n1</smiles>
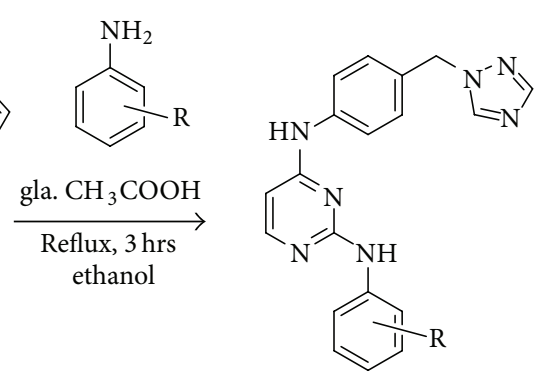

General structure BKD-1 to BKD-5

FIGURE 1: The reaction scheme of pyrimidine derivatives.

aluminum coated TLC plates Gel 60 F254 (E. Merck)). The reaction scheme is given in Figure 1.

2.3. Spectroscopy Study. Spectroscopic study of all the synthesized compounds was done by IR, ${ }^{1} \mathrm{H}$ NMR, and mass spectroscopy. IR spectra were recorded on $\mathrm{KBr}$ discs, using FT-IR (Shimadzu Spectrophotometer Model no.-8400). ${ }^{1} \mathrm{H}-$ NMR spectra were taken on a Bruker AVANCE II 400. In all the cases, NMR spectra were obtained in DMSO- $\mathrm{d}_{6}$ using TMS as an internal standard. The NMR signals are reported in $\delta \mathrm{ppm}$. Mass spectra were determined using direct inlet probe on a GCMS-QP-2010 mass spectrometer. Melting points of compounds were measured by Differential Scanning Calorimeter (Shimadzu-DSC-60).

2.4. Solubility Measurements. The solubility was measured by a gravimetric method [9]. For each measurement, an excess mole of compound was added to a known mole of solvent. Then, the equilibrium cell was heated to a constant temperature with continuous stirring. After at least $3 \mathrm{~h}$ (the temperature of the water bath approached constant value, and then the actual value of the temperature was recorded), the stirring was stopped and the solution was kept still for $2 \mathrm{~h}$. A portion of this solution was filtered and by a preheated injector, $2 \mathrm{~mL}$ of this clear solution was taken in another weighed measuring vial $\left(m_{0}\right)$. The vial was quickly and tightly closed and weighed $\left(m_{1}\right)$ to determine the mole of the sample $\left(m_{1}-m_{0}\right)$. Then, the vial was covered with a piece of filter paper to prevent dust contamination. After the solvent in the vial had completely evaporated at room temperature, the vial was dried and reweighed $\left(m_{2}\right)$ to determine the mole of the constant residue solid $\left(m_{2}-m_{0}\right)$. All the moles were taken using an electronic balance (Mettler Toledo AB204$\mathrm{S}$, Switzerland) with an uncertainty of $\pm 0.0001 \mathrm{~g}$. Thus, the concentration of the solid sample in the solution, mole fraction $x$, could be determined from

$$
x=\frac{\left(m_{2}-m_{0}\right) / M_{1}}{\left(m_{2}-m_{0}\right) / M_{1}+\left(m_{1}-m_{2}\right) / M_{2}},
$$

where $M_{1}$ is the molar mole of compound and $M_{2}$ is the molar mole of the solvent.

At each temperature, the measurement was repeated three times and an average value is given in Table 3.
TABLE 1: Physical properties of synthesized pyrimidine derivatives.

\begin{tabular}{lcccc}
\hline Sr. no. & Code & $\mathrm{R}$ & M.F & M.P. \\
\hline 1 & BKD-1 & $4-\mathrm{Cl}$ & $\mathrm{C}_{19} \mathrm{H}_{16} \mathrm{ClN}_{7}$ & 130.31 \\
2 & BKD-2 & $4-\mathrm{CH}_{3}$ & $\mathrm{C}_{20} \mathrm{H}_{19} \mathrm{~N}_{7}$ & 160.64 \\
3 & BKD-3 & $4-\mathrm{F}$ & $\mathrm{C}_{19} \mathrm{H}_{16} \mathrm{FN}_{7}$ & 197.35 \\
4 & BKD-4 & $3-\mathrm{CF}_{3}$ & $\mathrm{C}_{20} \mathrm{H}_{16} \mathrm{~F}_{3} \mathrm{~N}_{7}$ & 205.87 \\
5 & BKD-5 & $3-\mathrm{Cl}, 4-\mathrm{F}$ & $\mathrm{C}_{19} \mathrm{H}_{15} \mathrm{ClFN}_{7}$ & 225.82 \\
\hline
\end{tabular}

\section{Results and Discussion}

The physical properties of all the synthesized compounds are given in Table 1. For compound BKD-5, IR and ${ }^{1} \mathrm{H}$ NMR spectra are shown in Figures 2 and 3, respectively.

3.1. IR Spectra. The IR spectrum of BKD-5 is depicted in Figure 2. The IR data of BKD-5 clearly shows a $-\mathrm{NH}$ (secondary) stretching band at 3396 and $3196 \mathrm{~cm}^{-1}$. The IR stretching bands at $3090-2987 \mathrm{~cm}^{-1}$ and $1651-1494 \mathrm{~cm}^{-1}$ confirmed the presence of aromatic $\mathrm{C}-\mathrm{H}$ and $\mathrm{C}=\mathrm{C}$ in basic skeleton. The absorption band at $758 \mathrm{~cm}^{-1}$ and $1062-972$ indicates presence of $\mathrm{C}-\mathrm{Cl}$ and $\mathrm{C}-\mathrm{F}$ stretching present in synthesized compounds and IR stretching band at $1379 \mathrm{~cm}^{-1}$ indicates presence of triazole ring in synthesized compound. The bending vibration $-\mathrm{CH}_{2}$ was observed at $1462 \mathrm{~cm}^{-1}$, respectively. The $\mathrm{C}-\mathrm{H}$ symmetric stretching and asymmetric stretching absorption are observed at $2833 \mathrm{~cm}^{-1}$ and $2850 \mathrm{~cm}^{-1}$, respectively. All the IR group frequencies were suggestive of the fact that pyrimidine derivative is prepared successfully.

3.2. ${ }^{1} H-N M R$ Spectra. The proton NMR spectrum of BKD5 is depicted in Figure 3. The peak due to residual DMSO was observed at about $3.505 \delta \mathrm{ppm}$. It can be seen from the chemical structure of compound BKD-5 that proton of the phenyl ring attached to the carbons appeared as an appropriate multiplicity in the aromatic region at $6.463-$ $8.698 \delta \mathrm{ppm}$. The protons, which were present in methylene $\left(-\mathrm{CH}_{2}\right)$ (attached to phenyl ring and triazole ring), appeared as a singlet at $5.421 \delta \mathrm{ppm}$. The other two characteristic $-\mathrm{NH}$ groups appeared as a singlet at $10.527 \delta \mathrm{ppm}$ and $10.8 \delta \mathrm{ppm}$. 


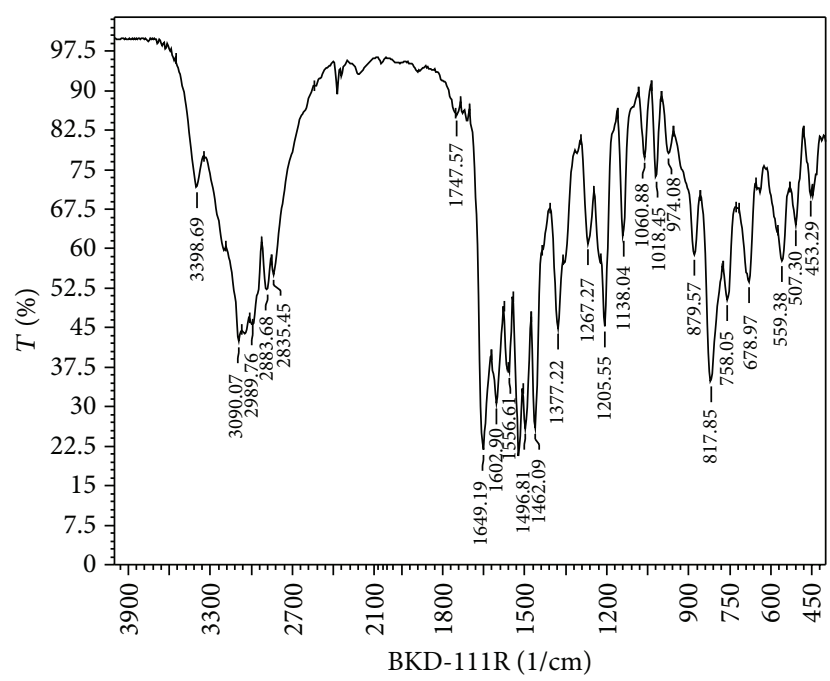

FIGURE 2: IR spectrum of compound BKD-5.

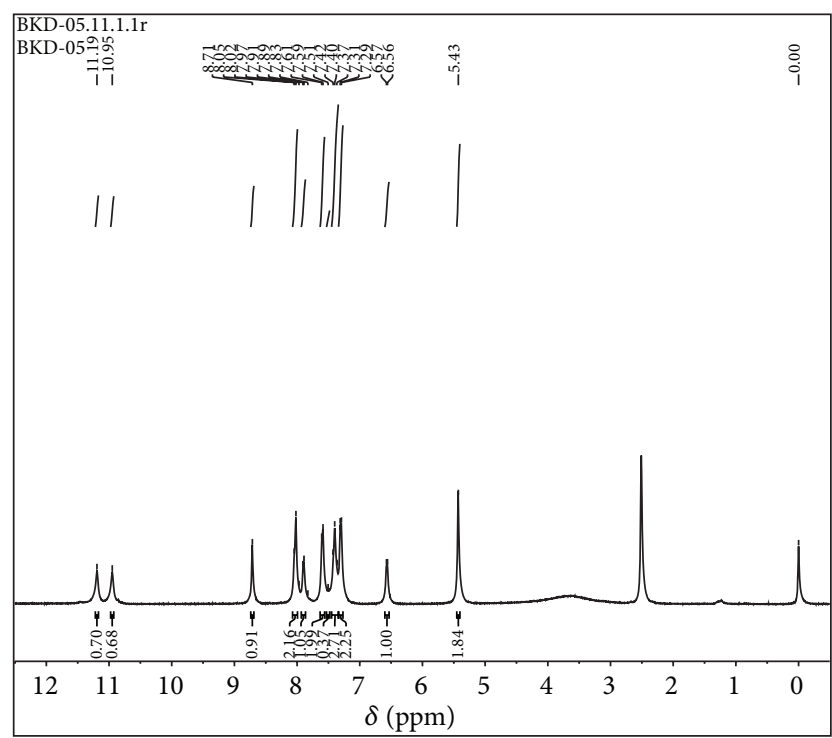

FIGURE $3:{ }^{1} \mathrm{H}$ NMR spectrum of compound BKD-5.

TABLE 2: Dielectric constant and dipole moment of solvents.

\begin{tabular}{lccc}
\hline Sr. no. & Solvent & Dielectric constant & Dipole moment \\
\hline 1 & Methanol & 32.70 & 1.7 \\
2 & $\mathrm{DMF}$ & 36.71 & 3.86 \\
3 & $\mathrm{CCl}_{4}$ & 2.238 & 0 \\
\hline
\end{tabular}

3.3. Solubility Measurements. The solubility of the compounds in methanol, DMF, and $\mathrm{CCl}_{4}$ is summarized in Table 3 at temperatures ranging from 298.15 to $328.15 \mathrm{~K}$. It is observed that for all the compounds, solubility is found to increase with temperature and order of solubility is DMF > methanol $>\mathrm{CCl}_{4}$. These solubility results are correlated with the dielectric constant and dipole moment of solvents which are given in Table 2. It is observed from Table 2 that both dielectric constant and dipole moment are higher for DMF

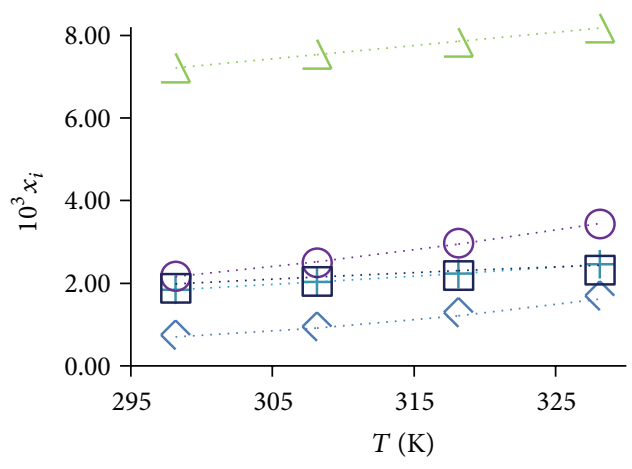

(a)

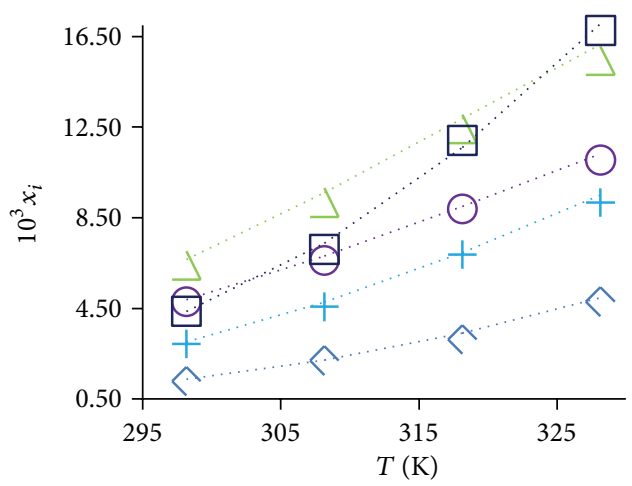

(b)

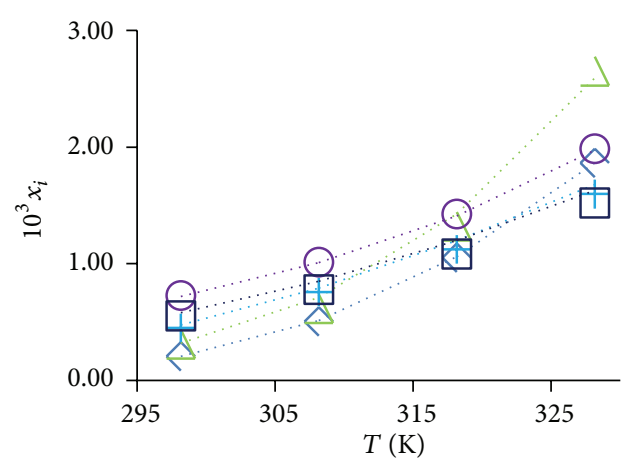

(c)

FIGURE 4: Variation of mole fraction solubilities $\left(x_{i}\right)$ with temperature for pyrimidine derivatives, (a) in methanol, (b) in DMF, and (c) in $\mathrm{CCl}_{4}$. BKD-1 $(\diamond), \mathrm{BKD}-2(\Delta), \mathrm{BKD}-3(+), \mathrm{BKD}-4(\bigcirc)$, and BKD-5 (). Dotted lines: $x_{c i}$.

and lower for $\mathrm{CCl}_{4}$. This is in accordance with the solubility trend in the three solvents. Thus, in present study, these properties affect the solubility. The variation of solubility in studied solvent with temperature is also shown in Figure 4.

The temperature dependence of solubility of compounds in solvents is described by the modified Apelblat equation [10, 11]. Consider

$$
\ln x_{c i}=A+\frac{B}{T}+C \ln (T),
$$

where $x_{c i}$ is the mole fraction solubility of compound, $T$ is the absolute temperature, and $A, B$, and $C$ are constants 
TABLE 3: Observed mole fraction solubilities $\left(x_{i}\right)$, calculated mole fraction solubilities $\left(x_{\mathrm{c} i}\right)$, and relative deviation (RD) of pyrimidine derivatives in studied solvents.

\begin{tabular}{|c|c|c|c|c|c|c|}
\hline$T / K$ & $10^{3} \cdot x_{i}$ & $\begin{array}{l}10^{3} \cdot x_{\mathrm{c} i} \\
\text { Methanol }\end{array}$ & $100 \mathrm{RD}$ & $10^{3} \cdot x_{i}$ & $\begin{array}{r}10^{3} \cdot x_{\mathrm{c} i} \\
\mathrm{DMF}\end{array}$ & $100 \mathrm{RD}$ \\
\hline & \multicolumn{6}{|c|}{ BKD-1 } \\
\hline 298.15 & 0.7424 & 0.7032 & 5.2714 & 1.2858 & 1.3644 & -6.1101 \\
\hline 308.15 & 0.9546 & 0.9179 & 3.8396 & 2.1772 & 2.2143 & -1.7032 \\
\hline 318.15 & 1.2917 & 1.2125 & 6.1314 & 3.1280 & 3.3990 & -8.6658 \\
\hline \multirow[t]{2}{*}{328.15} & 1.6961 & 1.6178 & 4.6146 & 4.7797 & 4.9642 & -3.8605 \\
\hline & \multicolumn{6}{|c|}{ BKD-2 } \\
\hline 298.15 & 7.2089 & 7.2173 & -0.1160 & 6.4013 & 6.6624 & -4.0791 \\
\hline 308.15 & 7.5441 & 7.5349 & 0.1224 & 9.1663 & 9.6171 & -4.9179 \\
\hline 318.15 & 7.8357 & 7.8549 & -0.2447 & 12.4275 & 12.8846 & -3.6788 \\
\hline \multirow[t]{2}{*}{328.15} & 8.1781 & 8.1773 & 0.0096 & 15.4508 & 16.1567 & -4.5692 \\
\hline & \multicolumn{6}{|c|}{ BKD-3 } \\
\hline 298.15 & 1.8396 & 1.8414 & -0.0994 & 2.9352 & 3.0049 & -2.3744 \\
\hline 308.15 & 2.0265 & 2.0266 & -0.0060 & 4.5676 & 4.7638 & -4.2964 \\
\hline 318.15 & 2.2303 & 2.2336 & -0.1457 & 6.8753 & 6.9688 & -1.3609 \\
\hline \multirow[t]{2}{*}{328.15} & 2.4631 & 2.4642 & -0.0462 & 9.1798 & 9.4912 & -3.3916 \\
\hline & \multicolumn{6}{|c|}{ BKD-4 } \\
\hline 298.15 & 2.1697 & 2.1656 & 0.1879 & 4.7890 & 4.8779 & -1.8557 \\
\hline 308.15 & 2.4994 & 2.5239 & -0.9774 & 6.6104 & 6.8106 & -3.0278 \\
\hline 318.15 & 2.9719 & 2.9472 & 0.8294 & 8.8903 & 9.0000 & -1.2333 \\
\hline \multirow[t]{2}{*}{328.15} & 3.4326 & 3.4465 & -0.4054 & 11.0513 & 11.3250 & -2.4764 \\
\hline & \multicolumn{6}{|c|}{ BKD-5 } \\
\hline 298.15 & 1.8804 & 1.9788 & -5.2320 & 4.3717 & 4.3519 & 0.4518 \\
\hline 308.15 & 2.0425 & 2.1480 & -5.1682 & 7.1020 & 7.3718 & -3.7998 \\
\hline 318.15 & 2.1859 & 2.3010 & -5.2636 & 11.9189 & 11.5947 & 2.7203 \\
\hline 328.15 & 2.3156 & 2.4359 & -5.1961 & 16.7816 & 17.0697 & -1.7170 \\
\hline \multirow{3}{*}{$T / K$} & $10^{3} \cdot x_{i}$ & $10^{3} \cdot x_{\mathrm{c} i}$ & $100 \mathrm{RD}$ & $10^{3} \cdot x_{i}$ & $10^{3} \cdot x_{\mathrm{c} i}$ & $100 \mathrm{RD}$ \\
\hline & \multicolumn{6}{|c|}{$\mathrm{CCl}_{4}$} \\
\hline & \multicolumn{3}{|c|}{ BKD-1 } & \multicolumn{3}{|c|}{ BKD-2 } \\
\hline 298.15 & 0.2086 & 0.2063 & 1.0639 & 0.3117 & 0.3199 & -2.6167 \\
\hline 308.15 & 0.5074 & 0.5129 & -1.0775 & 0.6170 & 0.7129 & -15.5464 \\
\hline 318.15 & 1.0532 & 1.0611 & -0.7491 & 1.3231 & 1.4269 & -7.8428 \\
\hline \multirow[t]{2}{*}{328.15} & 1.8654 & 1.8655 & -0.0074 & 2.6507 & 2.5944 & 2.1236 \\
\hline & \multicolumn{3}{|c|}{ BKD-3 } & \multicolumn{3}{|c|}{ BKD-4 } \\
\hline 298.15 & 0.4526 & 0.4792 & -5.8771 & 0.7293 & 0.7230 & 0.8634 \\
\hline 308.15 & 0.7606 & 0.7935 & -4.3353 & 1.0161 & 1.0104 & 0.5649 \\
\hline 318.15 & 1.1252 & 1.2016 & -6.7924 & 1.4272 & 1.4121 & 1.0633 \\
\hline \multirow[t]{2}{*}{328.15} & 1.5984 & 1.6805 & -5.1353 & 1.9872 & 1.9724 & 0.7442 \\
\hline & & BKD-5 & & & & \\
\hline 298.15 & 0.5563 & 0.5807 & -4.3813 & & & \\
\hline 308.15 & 0.7813 & 0.8526 & -9.1205 & & & \\
\hline 318.15 & 1.0849 & 1.2004 & -10.6449 & & & \\
\hline 328.15 & 1.5232 & 1.6278 & -6.8658 & & & \\
\hline
\end{tabular}

determined by least square analysis and values of these constants are given in Table 4 . The calculated solubilities $x_{c i}$ are also reported in Table 3 . The experimental solubility $\left(x_{i}\right)$ of synthesized compounds in the studied solvents was compared with calculated solubility $\left(x_{c i}\right)$ and relative deviations (RD) between the experimental and calculated value are calculated by the following equation:

$$
\mathrm{RD}=\left(\frac{x_{i}-x_{c i}}{x_{i}}\right)
$$

and the values are given in Table 3. 
TABLE 4: Constants $A, B$, and $C$ of (2), ARD and RMSD of pyrimidine derivatives in studied solvents.

\begin{tabular}{|c|c|c|c|c|c|}
\hline Para & BKD-1 & BKD-2 & BKD-3 & BKD-4 & BKD-5 \\
\hline & \multicolumn{5}{|c|}{ Methanol } \\
\hline$A$ & -188.055 & -11.7269 & -52.2145 & -77.6811 & 49.6358 \\
\hline$B$ & 6084.210 & -29.1148 & 1325.46 & 2035.83 & -3161.55 \\
\hline C & 28.150 & 1.2097 & 7.2786 & 11.3586 & -7.9434 \\
\hline $10^{5}$ RMSD & 3.5676 & 0.6605 & 0.1126 & 1.0857 & 6.3598 \\
\hline \multirow[t]{2}{*}{$100 \mathrm{ARD}$} & 4.964265 & -0.05721 & -0.07432 & -0.09137 & -5.21496 \\
\hline & \multicolumn{5}{|c|}{ DMF } \\
\hline$A$ & 174.3 & 345.3 & 346.99 & 229.015 & 280.85 \\
\hline$B$ & -11941.99 & -18676.27 & -19519.51 & -13181.27 & -17033.54 \\
\hline$C$ & -24.72 & -50.49 & -50.43 & -33.37 & -40.22 \\
\hline $10^{5}$ RMSD & 9.7924 & 28.56 & 11.145 & 10.602 & 14.764 \\
\hline \multirow[t]{2}{*}{$100 \mathrm{ARD}$} & -5.08489 & 4.31126 & -2.85585 & -2.1483 & -0.58617 \\
\hline & \multicolumn{5}{|c|}{$\mathrm{CCl}_{4}$} \\
\hline$A$ & 850.32 & 392.96 & 387.99 & -136.24 & 121.48 \\
\hline$B$ & -45868.6 & -24351.6 & -21792.9 & 3214.51 & -8815.27 \\
\hline C & -123.73 & -56.047 & -56.61 & 20.75 & -17.44 \\
\hline $10^{5}$ RMSD & 0.2844 & 4.3974 & 3.4608 & 0.6593 & 4.9956 \\
\hline $100 \mathrm{ARD}$ & -0.19255 & -5.97058 & -5.53503 & 0.808956 & -7.75314 \\
\hline
\end{tabular}

The relative average deviations (ARD) and root-meansquare deviations (RMSD) calculated by (4) are listed in Table 4. Consider

$$
\begin{gathered}
\mathrm{ARD}=\frac{1}{N} \sum_{i}^{N} \frac{x_{i}-x_{c i}}{x_{i}} \\
\mathrm{RMSD}=\left[\sum_{i=1}^{N} \frac{\left(x_{c i}-x_{i}\right)^{2}}{N-1}\right]^{1 / 2},
\end{gathered}
$$

where $N$ is the number of experimental points and $x_{c i}$ is the solubility calculated by (2).

According to the Krug et al. [12] approach, the following modified Van't Hoff expression was used to determine the enthalpy of solution $\left(\Delta H_{\text {sol }}\right)$ :

$$
\left(\frac{\partial \ln x}{\partial\left(1 / T-1 / T_{\mathrm{hm}}\right)}\right)_{P}=-\frac{\Delta H_{\mathrm{sol}}}{R},
$$

where $\Delta H_{\text {sol }} / R$ is the apparent standard enthalpy energy charge for the solution process and $T_{\mathrm{hm}}$ is the harmonic mean of the experimental temperatures, which is evaluated by the following equation:

$$
T_{\mathrm{hm}}=\frac{n}{\sum_{1}^{n}(1 / T)},
$$

where $n$ is the number of experimental temperatures [13]. In the present case, the $T_{\mathrm{hm}}$ value obtained is $312.7505 \mathrm{~K}$. The value of $\Delta H_{\text {sol }}$ was obtained from the slope of the plot of $\ln x_{i}$ versus $(1 / T-1 / 312.7505)$ as shown in Figure 5 for methanol, $\mathrm{DMF}$, and $\mathrm{CCl}_{4}$.

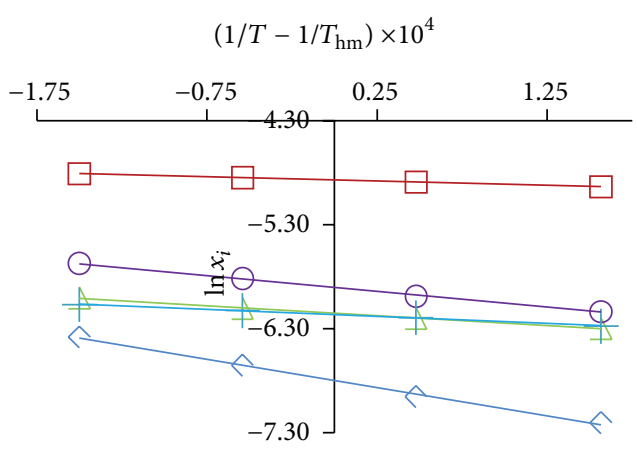

(a)

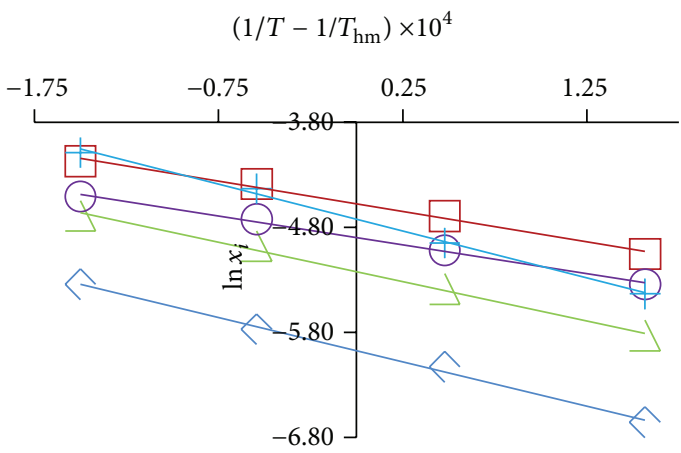

(b)

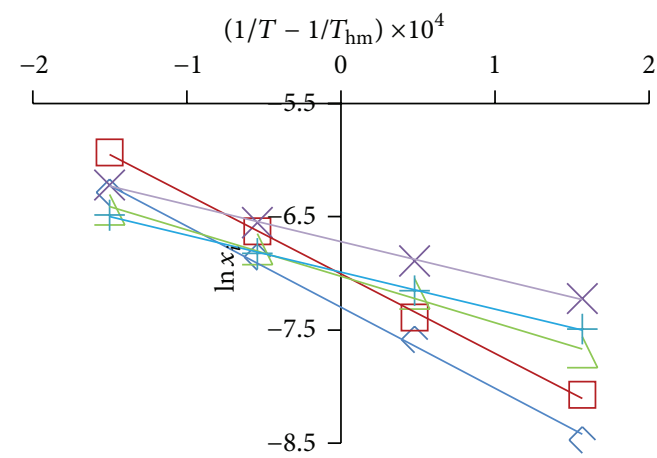

(c)

FIGURE 5: Van't Hoff plot for pyrimidine derivatives solubility in (a) in methanol, (b) in DMF, and (c) in $\mathrm{CCl}_{4}$. BKD-1 $(\diamond), \mathrm{BKD}-2(\square)$, BKD-3 $(\Delta)$, BKD-4 $(O)$, and BKD-5 (+).

The apparent standard Gibbs energy change for the solution process $\left(\Delta G_{\text {sol }}\right)$, considering the approach proposed by Krug et al., is calculated at $T_{\mathrm{hm}}$ by the following equation:

$$
\Delta G_{\text {sol }}=-\mathrm{RT} \cdot \text { Intercept }
$$

in which the intercept was from the plot of $\ln x$ versus $(1 / T-$ $\left.1 / T_{\mathrm{hm}}\right)$.

Finally, using these evaluated $\Delta H_{\text {sol }}$ and $\Delta G_{\text {sol }}$ values, the entropies of solutions $\Delta S_{\text {sol }}$ were obtained from equation [12, 14]

$$
\Delta S_{\mathrm{sol}}=\frac{\Delta H_{\mathrm{sol}}-\Delta G_{\mathrm{sol}}}{T_{\mathrm{hm}}} .
$$

All these thermodynamic parameters are given in Table 5. 
TABLE 5: Thermodynamic parameters of dissolution of pyrimidine derivatives in studied solvents.

\begin{tabular}{lccccc}
\hline Parameters & BKD-1 & BKD-2 & BKD-3 & BKD-4 & BKD-5 \\
\hline \multicolumn{5}{c}{ Methanol } \\
$\Delta G_{\mathrm{sol}} / \mathrm{kJ} \cdot \mathrm{mol}^{-1}$ & 17.6736 & 12.6578 & 15.9965 & 15.3516 & 16.0303 \\
$\Delta H_{\mathrm{sol}} / \mathrm{kJ} \cdot \mathrm{mol}^{-1}$ & 22.5891 & 3.3855 & 7.8958 & 12.5874 & 5.6410 \\
$\Delta S_{\mathrm{sol}} / \mathrm{J} \cdot \mathrm{mol}^{-1} \cdot \mathrm{K}^{-1}$ & 15.7171 & -29.6478 & -25.9014 & -8.8385 & -33.2189 \\
\hline \multicolumn{5}{c}{ DMF } \\
$\Delta G_{\text {sol }} / \mathrm{kJ} \cdot \mathrm{mol}^{-1}$ & 15.5336 & 11.8960 & 13.5783 & 12.7332 & 12.2834 \\
$\Delta H_{\mathrm{sol}} / \mathrm{kJ} \cdot \mathrm{mol}^{-1}$ & 35.0186 & 23.4372 & 31.2108 & 22.8552 & 37.0804 \\
$\Delta S_{\text {sol }} / \mathrm{J} \cdot \mathrm{mol}^{-1} \cdot \mathrm{K}^{-1}$ & 62.3018 & 36.9023 & 56.3787 & 32.3644 & 79.2870 \\
\hline & & \multicolumn{5}{c}{$\mathrm{CCl}$} \\
$\Delta G_{\text {sol }} / \mathrm{kJ} \cdot \mathrm{mol}^{-1}$ & 18.9815 & 18.2170 & 18.2716 & 17.4786 & 18.1754 \\
$\Delta H_{\text {sol }} / \mathrm{kJ} \cdot \mathrm{mol}^{-1}$ & 59.5282 & 58.3892 & 34.0375 & 27.2034 & 27.2283 \\
$\Delta S_{\text {sol }} / \mathrm{J} \cdot \mathrm{mol}^{-1} \cdot \mathrm{K}^{-1} 129.6456$ & 128.4480 & 50.4103 & 31.0944 & 28.9460 \\
\hline
\end{tabular}

It is evident from Table 5 that for all the compounds $\Delta H_{\text {sol }}$ and $\Delta G_{\text {sol }}$ values are positive. Further, $\Delta S_{\text {sol }}$ values are also positive for all compounds in $\mathrm{DMF}$ and $\mathrm{CCl}_{4}$ whereas it is negative in methanol excepting $\mathrm{BKD}-1$. When stronger bonds are broken and weaker bonds are formed, energy is consumed. So, $\Delta H_{\text {sol }}$ becomes positive [12] which indicates endothermic dissolution of compounds [15]. The positive value of $\Delta G_{\text {sol }}$ indicates that the dissolution process is not spontaneous $[12,15]$. The positive entropy change indicates that the entropy of solubilization is unfavorable for solute in solution [15], whereas negative entropy is due to more order in solutions [16]. This depends on the functional groups present in the compound as well as on the solvent. The negative entropy in methanol may be due to the fact that there may be hydrogen bonding between solute and solvent molecules which may give more ordered structure in solution, whereas in $\mathrm{DMF}$ and $\mathrm{CCl}_{4}$, due to larger structure (in comparison to methanol), the structure may be disrupted, thus giving positive entropy.

\section{Appendix}

\section{Spectral Data}

BKD-1: IR (cm $\left.{ }^{-1}, \mathrm{KBr}\right) .3375,3225$ (-NH (sec.) str.), 3095, 3036 (Ar-H str.), 2883 ( $-\mathrm{CH}_{2}$ asym. str.), 2833 ( $-\mathrm{CH}_{2}$ sym. str.), 1654-1489 ( $\mathrm{C}=\mathrm{C}$ str. Phenyl nucleus), $1456\left(-\mathrm{CH}_{2}\right.$ bending vib.), 1371 (triazole ring str.), 1273 (C-N str.), 1242-1010 (C$\mathrm{H}$ in plane bending, phenyl ring), 827 (C-H oop phenyl ring), 759 (C-Cl str.), 705-675 (C-H oop triazole ring), 626 (in plane pyrimidine ring bending), 422 (Out of plane pyrimidine ring bending). ${ }^{1} \mathrm{H} N M R\left(D M S O-d_{6}\right) \delta$ (ppm): $5.458(\mathrm{~s}, 2 \mathrm{H}), 6.559-6.575(\mathrm{~d}, 1 \mathrm{H}, J=6.4), 7.308-7.329(\mathrm{~d}$, $2 \mathrm{H}, J=8.4), 7.396-7.418(\mathrm{~d}, 2 \mathrm{H}, J=8.8), 7.518-7.538(\mathrm{~d}$, $2 \mathrm{H}, J=8), 7.583-7.601(\mathrm{~d}, 2 \mathrm{H}, J=7.2) 8.019-8.037(\mathrm{~d}, 1 \mathrm{H}$, $J=7.2), 8.095(\mathrm{~s}, 1 \mathrm{H}), 8.820(\mathrm{~s}, 1 \mathrm{H}), 10.984(\mathrm{~s}, 1 \mathrm{H}), 11.282(\mathrm{~s}$, 1H). MS: $(m / z)=377$.

BKD-2: IR ( $\left.\mathrm{cm}^{-1}, \mathrm{KBr}\right) .3394,3217$ (-NH (sec.) str.), 3088 (Ar$\mathrm{H}$ str.), 3041 ( $-\mathrm{CH}_{2}$ asym. str.), 2897 ( $-\mathrm{CH}_{3}$ sym. str.), 2837
( $-\mathrm{CH}_{2}$ sym str.), 1647-1516 ( $\mathrm{C}=\mathrm{C}$ str. Phenyl nucleus), 1460 ( $-\mathrm{CH}_{2}$ bending vib.), $1352\left(-\mathrm{CH}_{3}\right.$ asy bending) $1274(\mathrm{C}-\mathrm{N}$ str.), 1240-972 (C-H in plane bending, phenyl ring), 868-813 (C-H oop phenyl ring), 813 (C-Cl str.), 758 (C-H oop triazole ring). ${ }^{1} \mathrm{H} \mathrm{NMR}$ (DMSO-d $\left.{ }_{6}\right) \delta(p p m): 2.331$ (s, 3H), 5.425 (s, $2 \mathrm{H}), 6.432-6.449$ (d, $1 \mathrm{H}, J=6.8), 7.161-7.181(\mathrm{~d}, 2 \mathrm{H}, J=8)$, $7.249-7.270(\mathrm{~d}, 2 \mathrm{H}, J=8.4), 7.342-7.363(\mathrm{~d}, 2 \mathrm{H}, J=8.4)$, $7.592-7.612$ (d, 2H, $J=8$ ), 7.930-7.947 (d, 1H, $J=6.8), 8.016$ (s, 1H), 8.693 (s, 1H), $10.418(\mathrm{~s}, 1 \mathrm{H}), 10.873(\mathrm{~s}, 1 \mathrm{H}) . M S:(\mathrm{m} / z)$ $=357$.

BKD-3: IR ( $\left.\mathrm{cm}^{-1}, \mathrm{KBr}\right) .3391,3213$ (-NH (sec.) str.), 3059 (Ar$\mathrm{H}$ str.), 2893 ( $-\mathrm{CH}_{2}$ asym. str.), 1654-1506 (C=C str. Phenyl nucleus), 1462 ( $-\mathrm{CH}_{2}$ bending vib.), 1388 (triazole ring str), 1273 (C-N str.), 1219-1136 (C-H in plane bending, phenyl ring), 1018 (C-F str.), 835-768 (C-H oop phenyl ring), 767 (C-H oop triazole ring). ${ }^{1} \mathrm{H} \mathrm{NMR}\left(\mathrm{DMSO}_{-} \mathrm{d}_{6}\right) \delta(\mathrm{ppm}): 5.36$ (s, 2H), 6.2-6.214 (d, 1H, $J=5.6), 7.114-7.212(\mathrm{~m}, 4 \mathrm{H}), 7.22-$ $7.247(\mathrm{~m}, 1 \mathrm{H}), 7.605-7.627(\mathrm{~d}, 2 \mathrm{H}, J=8.8), 7.721-7.765(\mathrm{~m}$, $1 \mathrm{H}), 7.963-7.981(\mathrm{~d}, 2 \mathrm{H}, J=4), 8.635(\mathrm{~s}, 1 \mathrm{H}), 8.699(\mathrm{~s}, 1 \mathrm{H})$, $9.432(\mathrm{~s}, 1 \mathrm{H}) . \mathrm{MS}:(\mathrm{m} / \mathrm{z})=361$.

BKD-4: IR ( $\left.\mathrm{cm}^{-1}, \mathrm{KBr}\right) .3311,3203$ (-NH (sec.) str.), 31073041 (Ar-H str.), 2951 ( $-\mathrm{CH}_{2}$ asym. str.), 2883 (- $\mathrm{CH}_{2}$ sym str.), 1637-1491 (C=C str. Phenyl nucleus), $1456-1419\left(-\mathrm{CH}_{2}\right.$ bending vib.), 1334 (triazole ring str), 1271 (C-N str.), 12301157 (C-H in plane bending, phenyl ring), 1107-1014 (C-F str.), 966-848 (C-H oop phenyl ring), 794-650 (C-H oop triazole ring). ${ }^{1} \mathrm{H} N M R$ (DMSO-d $\left.{ }_{6}\right) \delta(p p m): 5.377(\mathrm{~s}, 2 \mathrm{H})$, 6.279-6.293 (d, 1H, $J=5.6), 7.222-7.257$ (t, 3H, $J=8)$, 7.434$7.474(\mathrm{t}, 1 \mathrm{H}, J=8), 7.686-7.707$ (d, 2H, $J=8.4), 7.996-8.012$ $(\mathrm{d}, 2 \mathrm{H}, J=6.4), 8.068-8.083(\mathrm{~d}, 1 \mathrm{H}, J=6), 8.175(\mathrm{~s}, 1 \mathrm{H})$, $8.654(\mathrm{~s}, 1 \mathrm{H}), 9.521(\mathrm{~s}, 2 \mathrm{H}) . M S:(\mathrm{m} / z)=411$.

BKD-5: IR ( $\left.\mathrm{cm}^{-1}, \mathrm{KBr}\right) .3396,3196$ (-NH (sec.) str.), 30902987 (Ar-H str.), 2850 (- $\mathrm{CH}_{2}$ asym. str.), $2833\left(-\mathrm{CH}_{2}\right.$ sym str.), 1651-1494 (C=C str. Phenyl nucleus), $1462\left(-\mathrm{CH}_{2}\right.$ bending vib.), 1379 (triazole ring str), 1265 (C-N str.), 1205, 1139 (C-H in plane bending, phenyl ring), 1060-972 (C-F str.), 879-819 (C-H oop phenyl ring), 758 (C-Cl str.), 680509 (C-H oop triazole ring). ${ }^{1} H$ NMR (DMSO-d $) \delta(p p m)$ : $5.421(\mathrm{~s}, 2 \mathrm{H}), 6.463-6.480(\mathrm{~d}, 1 \mathrm{H}, J=6.8), 7.286-7.307(\mathrm{~d}$, $2 \mathrm{H}, J=8.4), 7.333-7.353(\mathrm{~d}, 2 \mathrm{H}, J=8), 7.405-7.422(\mathrm{~d}, 2 \mathrm{H}$, $J=6.8), 7.903-7.920(\mathrm{~d}, 1 \mathrm{H}, J=6.8), 8.004-8.021(\mathrm{~d}, 2 \mathrm{H}$, $J=6.8), 8.685-8.698(\mathrm{~d}, 1 \mathrm{H}, J=5.2), 10.52(\mathrm{~s}, 1 \mathrm{H}), 10.8(\mathrm{~s}$, $1 \mathrm{H}) . M S:(m / z)=395$.

\section{Nomenclature}

$\begin{array}{ll}C: & \text { Concentration }\left(\mathrm{mol} \cdot \mathrm{L}^{-1}\right) \\ T: & \text { Absolute temperature }(\mathrm{K}) \\ x_{i}: & \text { Experimental solubility }\left(x_{i}\right) \\ x_{c i}: & \text { Calculated mole fraction solubility }\left(x_{c i}\right) \\ \Delta H_{\mathrm{sol}}: & \text { Enthalpy of solution } \\ G_{\mathrm{sol}}: & \text { Gibbs energies of dissolution }\left(\mathrm{kJ} \cdot \mathrm{mol}^{-1}\right) \\ \Delta S_{\mathrm{sol}}: & \text { Entropy of solutions }\left(\mathrm{kJ} \cdot \mathrm{mol}^{-1}\right) \\ R: & \text { Universal gas constant }\left(\mathrm{J} \cdot \mathrm{mol}^{-1} \cdot \mathrm{K}^{-1}\right) \\ T_{\mathrm{hm}}: & \text { Harmonic temperature }(\mathrm{K}) .\end{array}$

C: $\quad$ Concentration $\left(\mathrm{mol} \cdot \mathrm{L}^{-1}\right)$

$T: \quad$ Absolute temperature $(\mathrm{K})$

$x_{i}$ : $\quad$ Experimental solubility $\left(x_{i}\right)$

$x_{c i}: \quad$ Calculated mole fraction solubility $\left(x_{c i}\right)$

$\Delta H_{\text {sol }}$ : Enthalpy of solution

$G_{\text {sol }}:$ Gibbs energies of dissolution $\left(\mathrm{kJ} \cdot \mathrm{mol}^{-1}\right)$

$\Delta S_{\text {sol }}:$ Entropy of solutions $\left(\mathrm{kJ} \cdot \mathrm{mol}^{-1}\right)$

$T_{\mathrm{hm}}$ : Harmonic temperature (K). 


\author{
Abbreviations \\ DCP: 2,4-Dichloropyrimidine \\ TMA: $\quad 4-((1 H-1,2,4-$ Triazol-1-yl $)$ methyl)aniline \\ DIPEA: $N, N$-Diisopropylethylamine \\ DMF: $\quad N, N$-Dimethylformamide \\ $\mathrm{CCl}_{4}$ : Carbon tetrachloride \\ AR: Analytical reagent \\ AAD: Absolute average deviations \\ rmsd: Root-mean-square deviations \\ RD: Relative deviations.
}

\section{Conflict of Interests}

The authors of this paper do not have a direct financial relation with the commercial identity that might lead to a conflict of interests for any of the authors.

\section{References}

[1] M. Radi, S. Schenone, and M. Botta, "Recent highlights in the synthesis of highly functionalized pyrimidines," Organic \& Biomolecular Chemistry, vol. 7, no. 14, pp. 2841-2847, 2009.

[2] G. Hughes, C. Wang, A. S. Batsanov et al., "New pyrimidineand fluorene-containing oligo(arylene)s: synthesis, crystal structures, optoelectronic properties and a theoretical study," Organic \& Biomolecular Chemistry, vol. 1, pp. 3069-3077, 2003.

[3] K. Itami, D. Yamazaki, and J. Yoshida, "Pyrimidine-core extended $\pi$-systems: general synthesis and interesting fluorescent properties," Journal of the Americal Chemical Society, vol. 126, no. 47, pp. 15396-11537, 2004.

[4] J. Cieplik, M. Stolarczyk, J. Pluta et al., "Synthesis and antibacterial properties of pyrimidine derivatives," Acta Poloniae Pharmaceutica Drug Research, vol. 68, no. 1, pp. 57-65, 2011.

[5] M. S. Mohamed, S. M. Awad, and N. M. Ahmed, "Synthesis and antimicrobial activities of new indolyl-pyrimidine derivatives," Journal of Applied Pharmaceutical Science, vol. 1, no. 5, pp. 7680, 2011.

[6] R. Morgan, R. J. Haritakul, and P. A. Keller, "Antimalarial activity of 2,4-diaminopyrimidines," Letters in Drug Design \& Discovery, vol. 5, no. 4, pp. 277-280, 2008.

[7] B. Ramesh and S. V. Kulakarni, "Design, synthesis and anticancer activity of some new pyrimidine derivatives," Journal of Global Pharma Technology, vol. 2, no. 4, pp. 110-112, 2010.

[8] J. A. Riddick, W. B. Bunger, and T. Sakano, "Organic solventsphysical properties and methods of purification, techniques of chemistry," New York, NY, USA, 1986.

[9] M. Zhu, "Solubility and density of the disodium salt hemiheptahydrate of ceftriaxone in water + ethanol mixtures," Journal of Chemical \& Engineering Data, vol. 46, no. 2, pp. 175-176, 2001.

[10] Q.-S. Li, M.-G. Su, and S. Wang, "Solubility of 2-(4-ethylbenzoyl)benzoic acid in eleven organic solvents between 279.55 $\mathrm{K}$ and $343.15 \mathrm{~K}$," Journal of Chemical \& Engineering Data, vol. 52, no. 6, pp. 2477-2479, 2007.

[11] A. Daneshfar, H. S. Ghaziaskar, and N. Homayoun, "Solubility of gallic acid in methanol, ethanol, water, and ethyl acetate," Journal of Chemical \& Engineering Data, vol. 53, no. 3, pp. 776778, 2008.

[12] R. R. Krug, W. G. Hunter, and R. A. Grieger, "Enthalpy-entropy compensation. 2. Separation of the chemical from the statistical effect," The Journal of Physical Chemistry, vol. 80, no. 21, pp. 2341-2351, 1976.

[13] D. M. Aragón, M. A. Ruidiaz, E. F. Vargas et al., "Solubility of the antimicrobial agent triclosan in organic solvents of different hydrogen bonding capabilities at several temperatures," Journal of Chemical \& Engineering Data, vol. 53, no. 11, pp. 2576-2580, 2008.

[14] S. P. Bustamante, A. P. Romero, B. Escalera, and A. Reillo, "Nonlinear enthalpy-entropy compensation for the solubility of drugs in solvent mixtures: paracetamol, acetanilide and nalidixic acid in dioxane-water," Journal of Pharmaceutical Sciences, vol. 87, no. 12, pp. 1590-1596, 1998.

[15] E. K. Panteli and E. K. Voutsas, "Solubilities of cinnamic acid esters in ionic liquids," Journal of Chemical \& Engineering Data, vol. 54, no. 3, pp. 812-818, 2009.

[16] A. A. El-Bindary, A. Z. El-Sonbati, E. H. El-Mosalamy, and R. M. Ahmed, "Potentiometric and thermodynamic studies of azosulfonamide drugs. X," Chemical Papers, vol. 57, no. 4, pp. 255-258, 2003. 

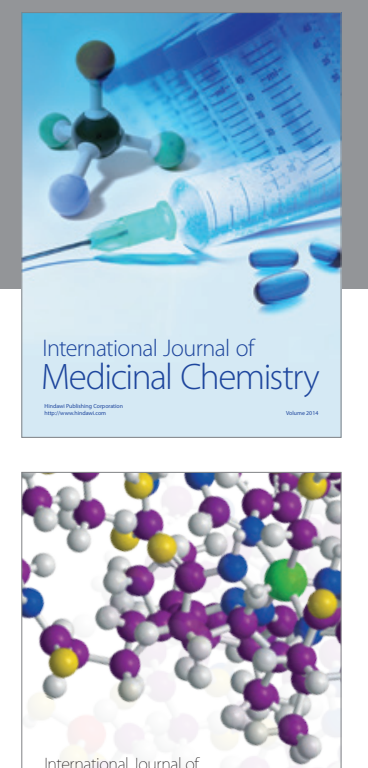

\section{Carbohydrate} Chemistry

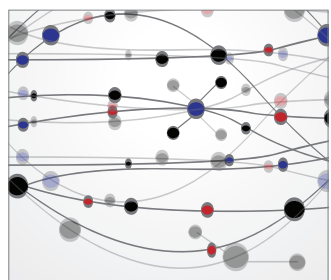

The Scientific World Journal
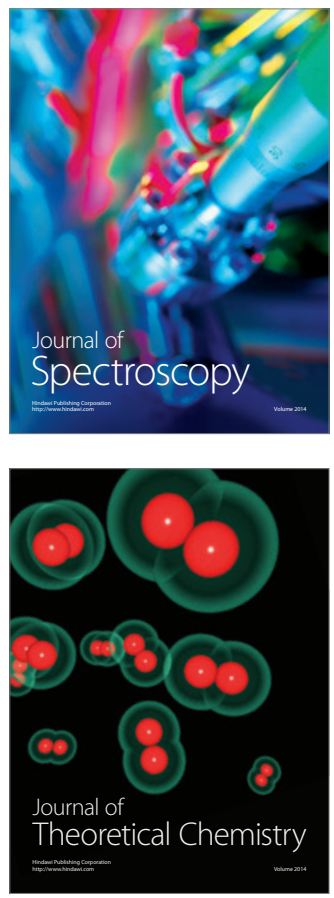
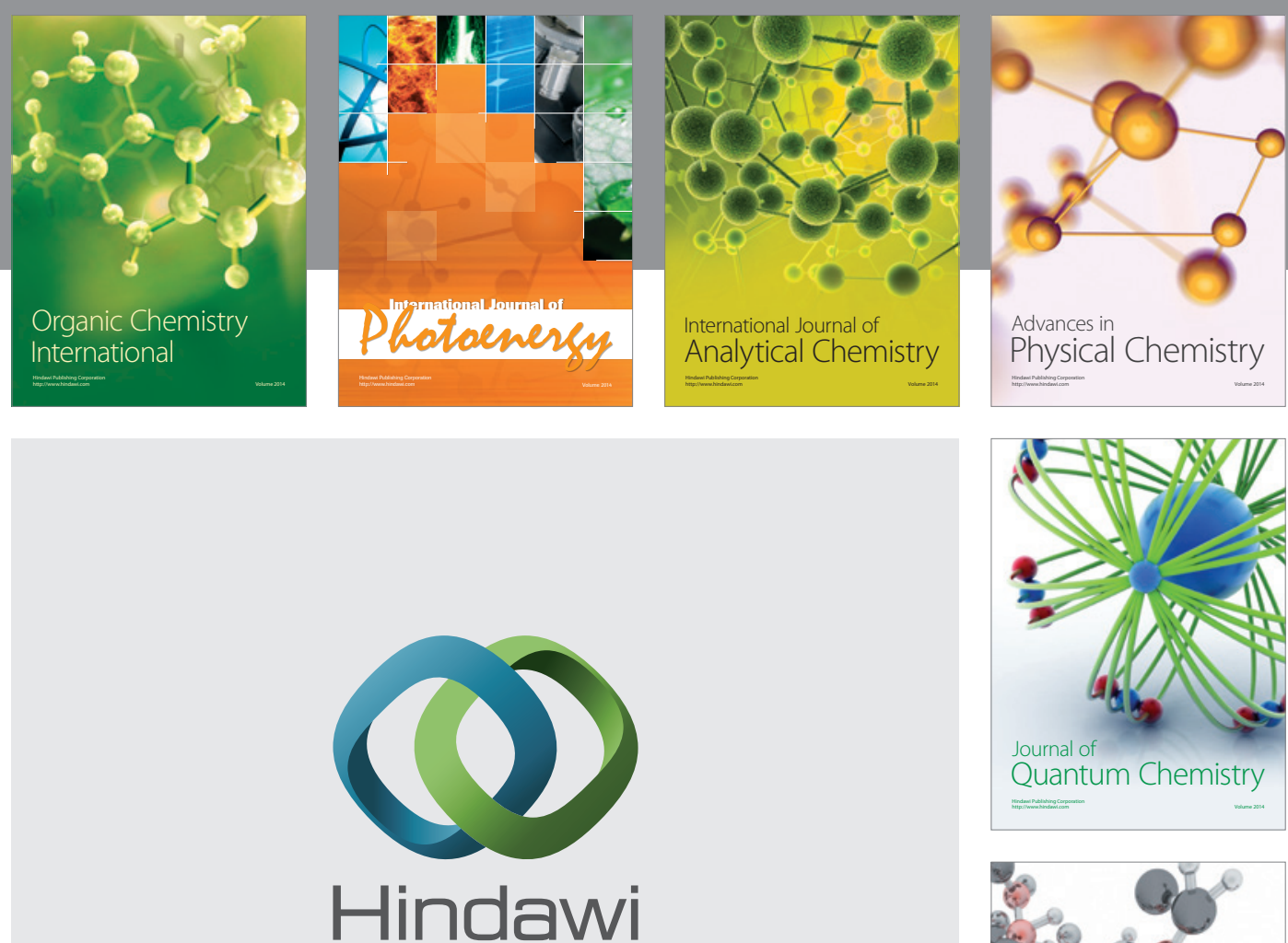

Submit your manuscripts at

http://www.hindawi.com

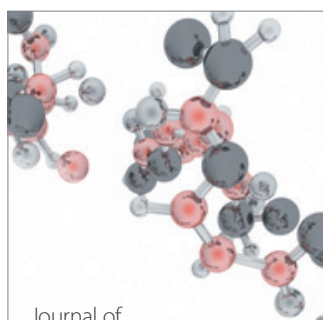

Analytical Methods

in Chemistry

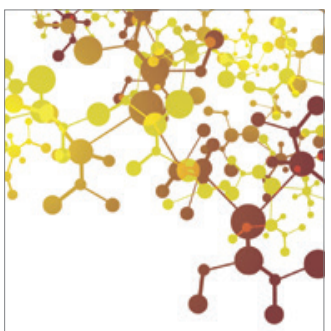

Journal of

Applied Chemistry

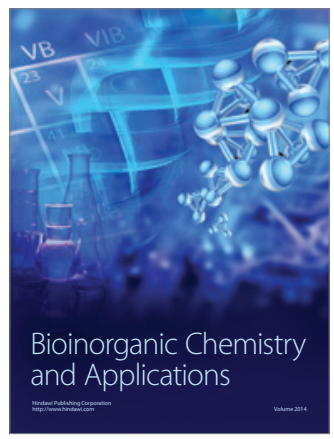

Inorganic Chemistry
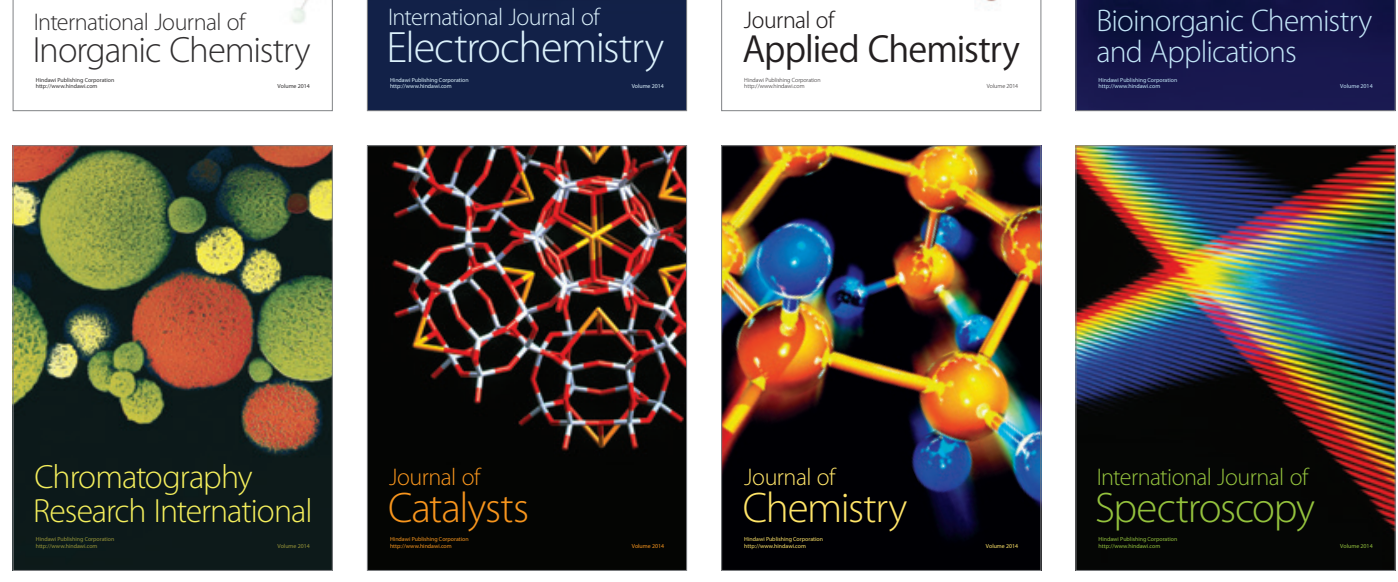